\title{
Effects of conditioning on the equivalent properties estimated by a discrete fracture network model
}

\author{
Radioactive Waste Disposal Research Division, Korea Atomic Energy Research Institute, Daejeon, 34057, Republic of Korea;
} *Corresponding author, E-mail:shji@kaeri.re.kr

(Received: April 5, 2020; Revised accepted: June 26, 2020)

https://doi.org/10.18814/epiiugs/2020/020071

The classical stochastic discrete fracture network (DFN) approach is an attempt to simulate the statistical characteristics of fractures in a site, and does not need to match the observed fractures. In this study, the effects of conditioning the stochastically generated fractures with the fracture mapping and geophysical survey data on the equivalent properties of a fracture system were evaluated. A hypothetical real fracture system was assumed, and the classical and conditional stochastic approaches were applied to simulate it. Then the equivalent network properties such as equivalent permeability and density of the percolating cluster were calculated and compared to each other. The comparison results showed that conditioning with the fracture mapping data improved the classical stochastic approach in estimating the geometric connection by the fracture network while the performance of the conditional stochastic models estimating the hydraulic connection was similar to the classical stochastic model.

\section{Introduction}

Crystalline rock is considered as the host rock for a high-level radioactive waste (HLW) disposal repositories in many countries such as Sweden and Finland (SKB, 2011; Posiva, 2012). To evaluate the safety of a subsurface repository for HLW, it is necessary to characterize the groundwater flow system of the disposal site and conceptualize it mathematically because groundwater flow is one of the major pathways for nuclides leaked from the repository. Groundwater flow in a crystalline rock is governed by fractures due to differences in the hydraulic properties between fractures and matrices. To represent fractures in a mathematical model that simulates groundwater flow, the equivalent continuum model (ECM) and the discrete fracture network (DFN) model were suggested. With the ECM, a fractured rock is assumed as a single continuum (e.g., Thury et al., 1994), a multiple continuum (e.g. Schwartz et al., 2010), or a stochastic continuum (e.g., Park et al., 2004). Although computationally efficient and straightforward to implement, ECM has a fundamental limitation due to the simplified representation of the fracture network (Ji et al., 2012; Ramasomanana et al., 2018;
Koohbor et al., 2020). The DFN model describes explicitly the fractures and can simulate flow and transport through them. Thus, it can account for heterogeneous and discrete natures of a fractured rock aquifer (Dershowitz et al., 1991). In the DFN model, fractures can be conceptualized with deterministic and stochastic approaches (Ji et al., 2011; Ji and Koh, 2017). The deterministic conceptualization approach is an attempt to describe the geometrical and hydraulic properties of individual fractures in a site explicitly, which is impractical in the realworld applications. Fractures are mostly generated stochastically in the DFN model with implicit group information for a population of fractures to reproduce its statistical properties, which is the stochastic conceptualization approach.

When fractures are constructed stochastically for a DFN model, an infinite number of fracture networks with various geometrical and hydraulic properties can be generated with the same statistical parameters. The stochastic DFN model can be considered sufficient to simulate groundwater flow in a given site if it guarantees similar hydraulic behaviors to the observations for different realizations (Bear, 1993). However, the variability of geometrical and hydraulic properties among the realizations is considered as uncertainty in the stochastic DFN approach (Ji et al., 2011). Because it reproduces the statistical properties of their population, the classical stochastic DFN model does not need to match the observed fractures at boreholes, tunnels, or outcrops exactly. Thus, stakeholders other than experts sometimes doubt the reliability of the results from the stochastic DFN modeling.

There have been several attempts to condition the stochastically generated fractures to match the observation in the field. Dershowitz et al. (2004) classified these attempts as geocellular and bootstrap approaches. In the geocellular approach, the modeling domain is discretized to cells, and fractures and their properties in the cell are generated based on the cell-based information such as geophysical and hydrogeological properties. La Pointe et al. (2004) suggested the possibility of reconstructing the fracture system for the Circle Ridge Field at Wind Basin, Wyoming, with the relation between the strain field and the fracture distribution properties such as intensity and orientation. The bootstrap approach uses the observations at specific locations directly to extrapolate the population of fractures. Dorn et al. (2013) conditioned the stochastically generated fracture networks for the Ploemeur Aquifer Test Site in Brittany, France with the borehole logging data, images of fractures from ground-penetrating radar (GPR) 
data and inferred connectivity between the boreholes from the tracer test results. After conditioning, the estimated transmissivity from the DFN models was agreed well with the estimated one from pumping, flowmeter and temperature data, but it still had large variations. Bym et al. (2014) proposed two algorithms for conditioning the stochastic DFN model with the fracture traces in the tunnel walls and/or boreholes. According to their algorithms, fractures were created stochastically after generating fractures from the traces, or the fractures crossing the tunnel walls and boreholes were adjusted based on the observed traces after stochastic generation of fractures.

In this study, the conditional stochastic DFN approaches were evaluated by comparing their performance to that of the classical stochastic DFN model. A fracture network, where the local fracture intensity had a linear relation with a seismic coherence, was created and assumed as a real fracture system. To represent the assumed real fracture system, the classical stochastic DFN model and the conditional stochastic DFN models with geocelluar, bootstrap, and hybrid approaches were applied. With the simulated fracture networks from each approach, the equivalent network properties such as equivalent permeability and density of the percolating cluster were calculated and compared to those of the hypothetic real fracture system. The performance of the conditional stochastic DFN approaches was then determined based on the results of comparison.

\section{Approaches}

\section{Hypothetical Real Fracture System}

To create a hypothetical real fracture system, the statistical properties of background fractures in the domain HRD1 of KAERI (Korea Atomic Energy Research Institute) URT (Underground Research Tunnel), hereafter KURT, site were used (Ji and Koh, 2017). Fig. 1 shows the location and layout of the KURT. It is a small-scale underground research facility whose maximum depth is about 120 $\mathrm{m}$ from the ground surface, and the host rock is a Mesozoic twomica granite. It is located in Daejeon, a Midwest region of the Korean peninsula. Table 1 indicates the statistical distribution models used to create a hypothetical real fracture system. Using the given distribution models, fractures of a hexagonal shape, inscribed in circles, were generated in a $100 \mathrm{~m} \times 100 \mathrm{~m} \times 100 \mathrm{~m}$ domain as the hypothetical real fracture system (Fig. 2a). The statistical properties of the generated fracture network are shown in Table 1, and they are almost the same as the original ones.

To obtain the deterministic information on the real fracture system for the conditional modeling, a linear relation between the fracture intensity and seismic coherence was assumed as follows:
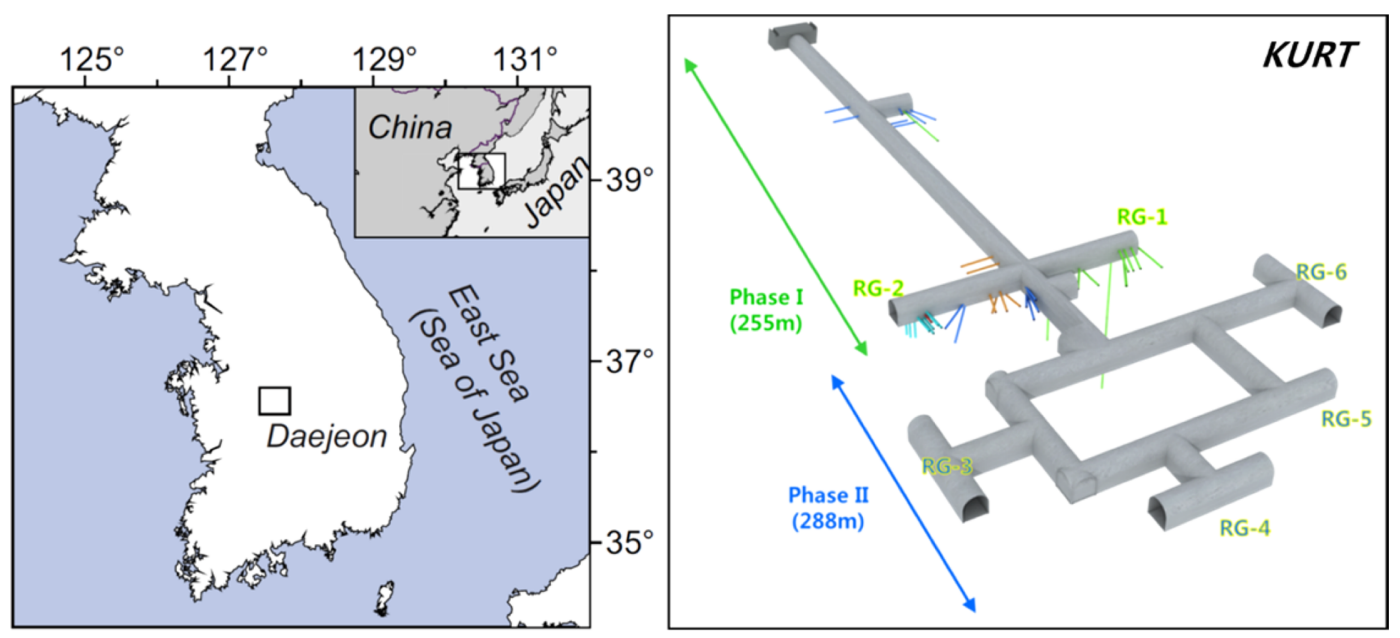

Figure 1. Location and layout of the KURT.

Table 1. Statistical distribution models for creating a hypothetical real fracture system, and resulting distribution models of the created fracture system

\begin{tabular}{|c|c|c|}
\hline Statistical distribution model & $\begin{array}{c}\text { Domain HRD1 of KURT site } \\
\text { [from Ji and Koh (2017)] }\end{array}$ & $\begin{array}{l}\text { Hypothetical real fracture system } \\
\text { in Fig. } 2 \mathrm{a}\end{array}$ \\
\hline Orientation & $\begin{array}{c}\text { Elliptical Fisher model } \\
\text { Mean pole }(\mathrm{tr}, \mathrm{pl})=\left(44^{\circ}, 26^{\circ}\right) \\
\text { Dispersion dir. }{ }^{\mathrm{a}}(\mathrm{tr}, \mathrm{pl})=\left(307^{\circ}, 14^{\circ}\right) \\
\mathrm{K}_{1}=4.6 \\
\mathrm{~K}_{2}=1.8\end{array}$ & $\begin{array}{c}\text { Elliptical Fisher model } \\
\text { Mean pole }(\mathrm{tr}, \mathrm{pl})=\left(43^{\circ}, 26^{\circ}\right) \\
\text { Dispersion dir. }{ }^{\mathrm{a}}(\mathrm{tr}, \mathrm{pl})=\left(307^{\circ}, 14^{\circ}\right) \\
\mathrm{K}_{1}=4.6 \\
\mathrm{~K}_{2}=1.5\end{array}$ \\
\hline Fracture transmissivity & $\begin{array}{c}\text { Lognormal distribution model } \\
\text { Mean }=2.5 \times 10^{-8} \mathrm{~m}^{2} / \mathrm{s} \\
\text { Std Dev. }=4.1 \times 10^{-8} \mathrm{~m}^{2} / \mathrm{s}\end{array}$ & $\begin{array}{c}\text { Lognormal distribution model } \\
\text { Mean }=2.5 \times 10^{-8} \mathrm{~m}^{2} / \mathrm{s} \\
\text { Std Dev. }=4.2 \times 10^{-8} \mathrm{~m}^{2} / \mathrm{s}\end{array}$ \\
\hline Fracture radius & $\begin{array}{c}\text { Lognormal distribution model } \\
\text { Mean }=2.6 \mathrm{~m} \\
\text { Std Dev. }=1.2 \mathrm{~m}\end{array}$ & $\begin{array}{c}\text { Lognormal distribution model } \\
\text { Mean }=2.5 \mathrm{~m} \\
\text { Std Dev. }=1.3 \mathrm{~m}\end{array}$ \\
\hline Density (P32) & 0.44 & 0.43 \\
\hline
\end{tabular}

${ }^{\mathrm{a}}$ Direction where orientation dispersion is greatest 


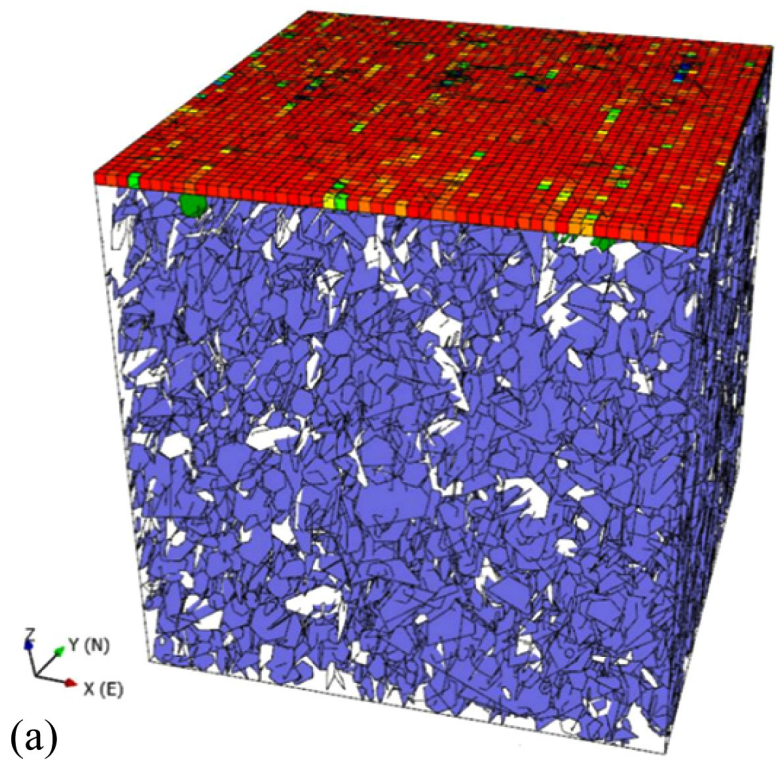

(b)

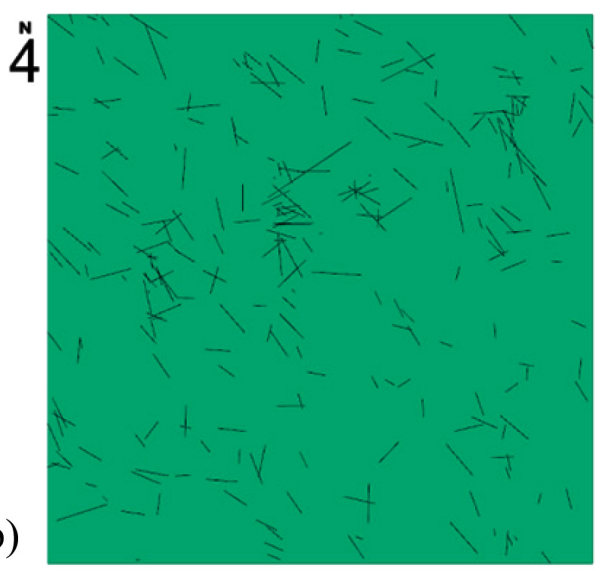

(c)
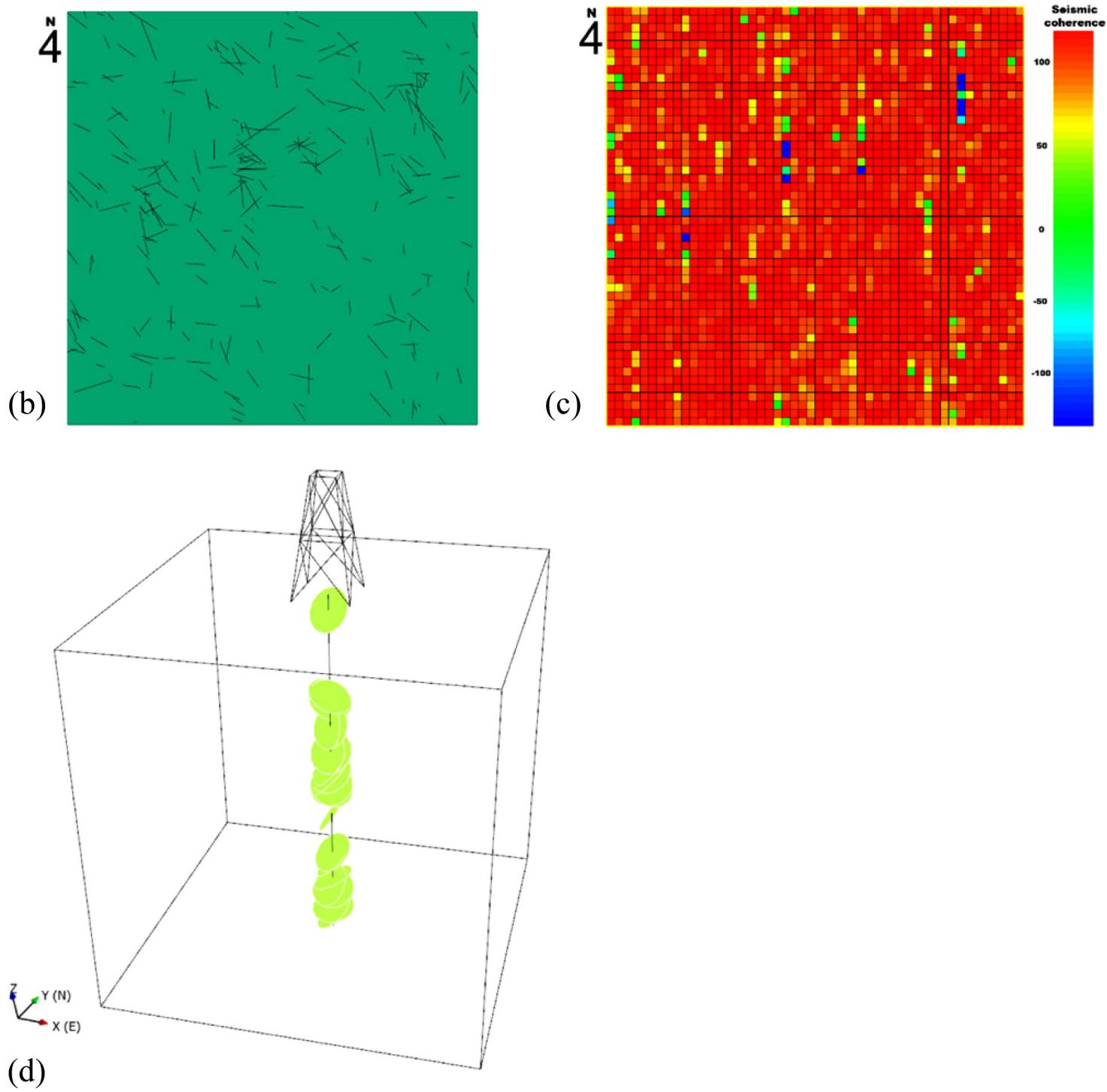

Figure 2. (a) Created hypothetical real fracture system, (b) its trace map, and (c) seismic coherence distribution map at the top boundary. (d) Logged fractures at the vertical borehole drilled from the center of the top. The seismic coherence distribution at the top boundary was introduced using the hypothetical real fracture system and equation (1), as shown in Fig. 2 a. 


$$
P 32=2-0.023 C_{h}
$$

where P32 is the fracture intensity defined as the total area of fractures per unit volume of the rock and $C_{h}$ is the seismic coherence. Then, the fracture trace and seismic coherence distribution maps at the top boundary of the domain were introduced from the hypothetic real fracture system and the linear relation of equation (1) (Figs. 2b and $2 \mathrm{c}$ ). A borehole was installed vertically at the center of the top boundary, and the fractures crossing that borehole were logged (Fig. $2 d)$. The fracture logging data was assumed to include the intersecting location and orientation of each fracture.

\section{Stochastic DFN Modeling}

To reproduce the hypothetical real fracture system, the classical and conditional stochastic DFN models were applied. For the classical stochastic DFN approach, fractures were randomly generated to follow the statistical distribution models of the hypothetical real fracture system given in Table 1 . The statistical properties of the generated fracture networks were checked by utilizing the FracMan program (Golder, 2018), and 200 network realizations were constructed for the statistical convergence of the results.

The bootstrap conditional stochastic DFN approach applied in this study was similar to that of Bym et al. (2014). Fractures were generated stochastically, and the crossed fractures with the top boundary were removed. With the trace map given by Fig. $2 b$, fractures crossing the top boundary were generated. Although their orientation and intersection with the top boundary were fixed, the size, transmissivity, and location of the center of the fractures were randomly generated with the distribution models in Table 1. After constructing a fracture network, its statistical properties were checked. For the statistical convergence of the results, 200 network realizations were generated with the bootstrap conditional stochastic DFN approach.

Another 200 fracture networks were also constructed using the geocellular conditional stochastic approach. Fractures were generated stochastically with the distribution models shown in Table 1, and the fractures near the top boundary were adjusted to match the fracture intensity distribution inferred from equation (1) and the seismic coherence distribution map shown in Fig. 2c.

For the hybrid conditional stochastic DFN approach, the seismic coherence distribution map at the top boundary and the fracture logging data at the installed borehole were used for conditioning. A fracture network was constructed stochastically and the fractures intersecting the borehole were removed. From the fracture logging data, then, the fractures intersecting the borehole were generated considering the distribution models in Table 1. For the last step, the fractures near the top boundary were adjusted using the seismic coherence distribution map. The statistical properties of the final fracture network were checked to see whether they were identical to those of the hypothetical real fracture system.

\section{Equivalent Properties of the Network}

To evaluate the performance of the stochastic models, the equivalent properties such as the density of the percolating cluster and the equivalent permeability were calculated among the fracture networks constructed with each approach. Their average behaviors among the realizations were then introduced from the Monte Carlo simulation.

The density of the percolating cluster $\left(\rho_{p c}\right)$ is defined as the ratio of the total area of the percolating cluster of fractures to the volume of the domain, and indicates the connectivity and geometric characteristics of the network (Stauffer and Aharony, 1991; Ji and Koh, 2017). The percolating cluster can be varied for different directions due to the fracture orientation distribution characteristics, and the $\rho_{p c}$ was calculated in the East-West (EW), North-South (NS), and Top-Bottom (TB) directions for each fracture network.

The equivalent permeability $\left(K_{\text {eqv }}\right)$ is related to the connectivity and hydraulic properties of the fracture network (Mourzenko et al., 2004; Bogdanov et al., 2007). To calculate the $K_{\text {equ }}$ the MAFIC program, which is a finite element code to simulate flow and transport in a rock with a discrete fracture network, was used (Miller et al., 1999). In MAFIC, the governing equation for the fluid flow in a fracture is given by:

$$
S \frac{\partial h}{\partial t}-T \nabla^{2} h=q
$$

where $S$ is the fracture storativity [dimensionless], $h$ is the hydraulic head $[\mathrm{L}], t$ is the time [T], $T$ is the fracture transmissivity $\left[\mathrm{L}^{2} / \mathrm{T}\right]$, and $q$ is the source term $[\mathrm{L} / \mathrm{T}]$. Mass conservation at a fracture intersection is assumed. Using the MAFIC program, a steady-state groundwater flow was simulated with constant boundary conditions at two opposite boundaries of the domain and no flow boundary conditions at the other four boundaries. The $K_{\text {eqv }}$ in the EW, NS, and TB directions for each fracture network was then calculated with the following equation:

$$
K_{e q v}=\frac{Q}{\left(h_{u p}-h_{d n}\right) L}
$$

where $Q$ is the fluid flux $\left[\mathrm{L}^{3} / \mathrm{T}\right]$ from the upstream to the downstream boundaries of the specified head values $h_{u p}[\mathrm{~L}]$ and $h_{d n}[\mathrm{~L}]$, respectively.

\section{Results and Discussion}

Using each stochastic DFN approach, fracture networks were generated to follow the statistical properties of the hypothetical real fracture system. Fig. 3 shows examples of the constructed fracture networks. The equivalent properties of the fracture networks were calculated, and they were averaged over the number of realizations for each case.

The density of the percolating cluster $\left(\rho_{p c}\right)$ indicates the intensity of fractures contributing to the geometric connections between one boundary to another boundary. The calculated $\rho_{p c}$ of the hypothetical real fracture system in the EW, NS, and TB directions was 0.281 , 0.282 and 0.279 , respectively (Fig. 4). Considering that the P32 of the real fracture system was 0.43 (Table 1), the calculated $\rho_{p c}$ shows that about $65 \%$ of all fractures in the domain contributed to a geometric connection between two opposite boundaries.

Fig. 4 indicates the mean $\rho_{p c}$ and coefficient of variation among the realizations generated with the classical, bootstrap conditional, geocellular conditional, and hybrid conditional stochastic approaches. The coefficient of variation (CV) is defined as the ratio of the standard deviation to the mean and has been used to evaluate the variability of 

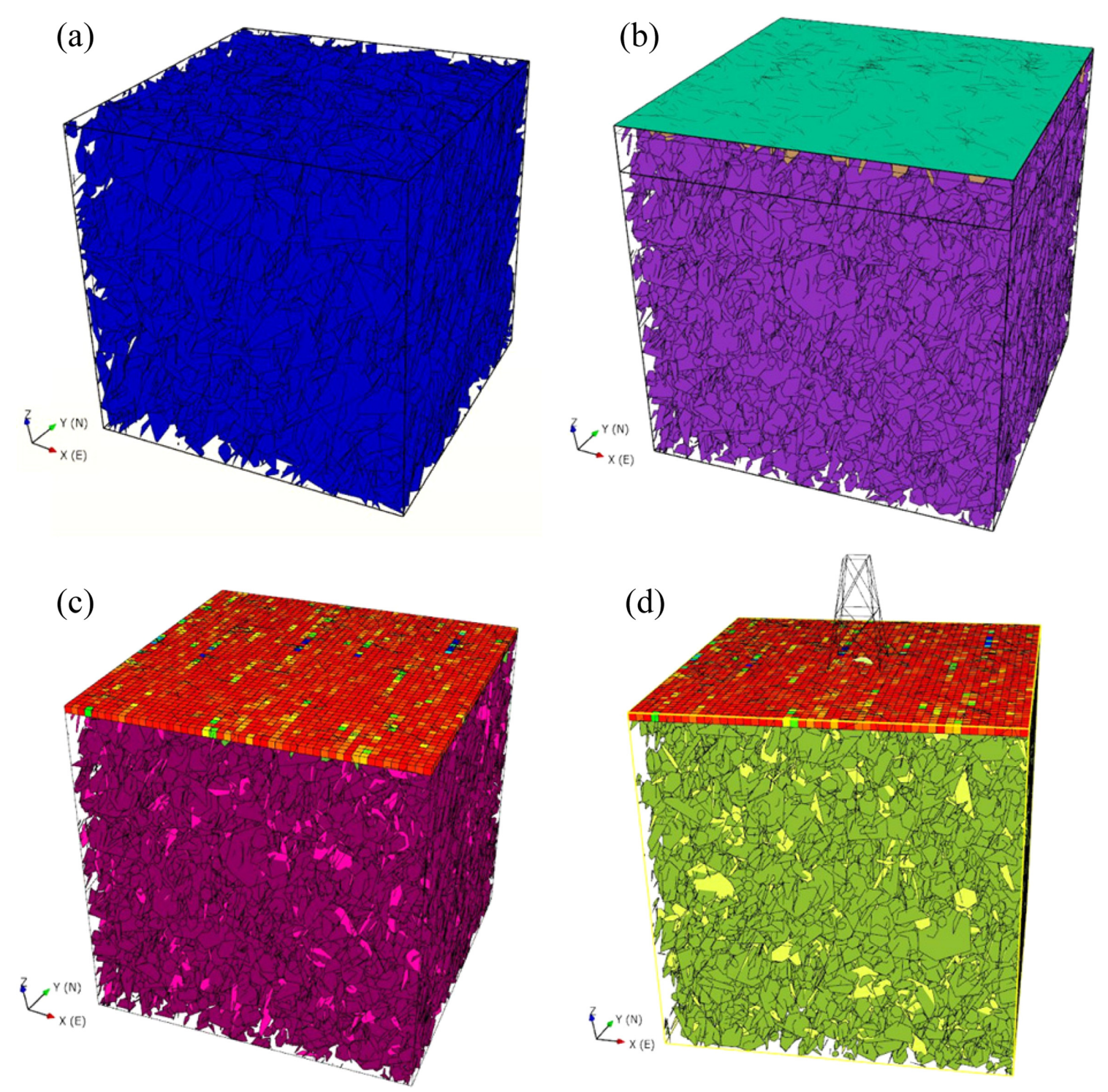

Figure 3. Examples of constructed DFNs from (a) the classical, (b) bootstrap conditional, (c) geocellular conditional, and (d) hybrid conditional stochastic DFN approaches.

the average behavior (Ji et al., 2011; Ji and Koh, 2017). The CV of $\rho_{p c}$ from various stochastic models were ranged from 0.010 to 0.012 , which means that the characteristic of geometric connection was very similar among the realizations. The $\mathrm{CV}$ of $\rho_{p c}$ from the classical model was smaller than those of the conditional models (Fig. 4), and this is because the statistical homogeneity of the stochastic models was disrupted by the fractures conditioning near the top boundary and the installed borehole. Since the fractures logged at the borehole were very small parts of the overall fracture system, the $\rho_{p c}$ of the fracture networks from the hybrid conditional model was almost identical to those from the geocellular conditional model. Regardless of the models, the mean $\rho_{p c}$ calculated was similar to those of the real fracture system in the range of $10 \%$, although those from the bootstrap conditional model was the closest. These results were because the geometric connection between the boundaries was strongly influenced by the fractures near the boundaries, and the fractures near the boundaries were fixed in the bootstrap conditional model.
The equivalent permeability $\left(K_{\text {eqv }}\right)$ is an indicator of how well one boundary is hydraulically connected to another boundary by the fracture network. The $K_{\text {eqv }}$ of the hypothetical real fracture system was $5.33 \times 10^{-10} \mathrm{~m} / \mathrm{s}, 4.91 \times 10^{-10} \mathrm{~m} / \mathrm{s}$ and $6.04 \times 10^{-10} \mathrm{~m} / \mathrm{s}$ in the EW, NS, and TB directions, respectively (Fig. 5).

Fig. 5 shows the mean $K_{e q v}$ and $\mathrm{CV}$ from various stochastic models. All CV of $K_{\text {eqv }}$ were less than 0.1, which means that the variability in the estimated $K_{e q v}$ from the statistical properties of the fractures was low. The CV of $K_{\text {eqv }}$ did not differ among the stochastic models, but it was about 1 order larger than the $\mathrm{CV}$ of $\rho_{p c}$. These results indicate that the hydraulic connection was more variable and uncertain than the geometric connection due to diverse preferential groundwater flow paths from various transmissivities among the fractures. The mean $K_{\text {eqv }}$ induced from the various stochastic models were all similar to the actual $K_{\text {eqv }}$ of the real fracture system in the range of $10 \%$. It is difficult to evaluate which model is good for estimating $K_{\text {eqv }}$ : The results from the classical and bootstrap conditional stochastic models 

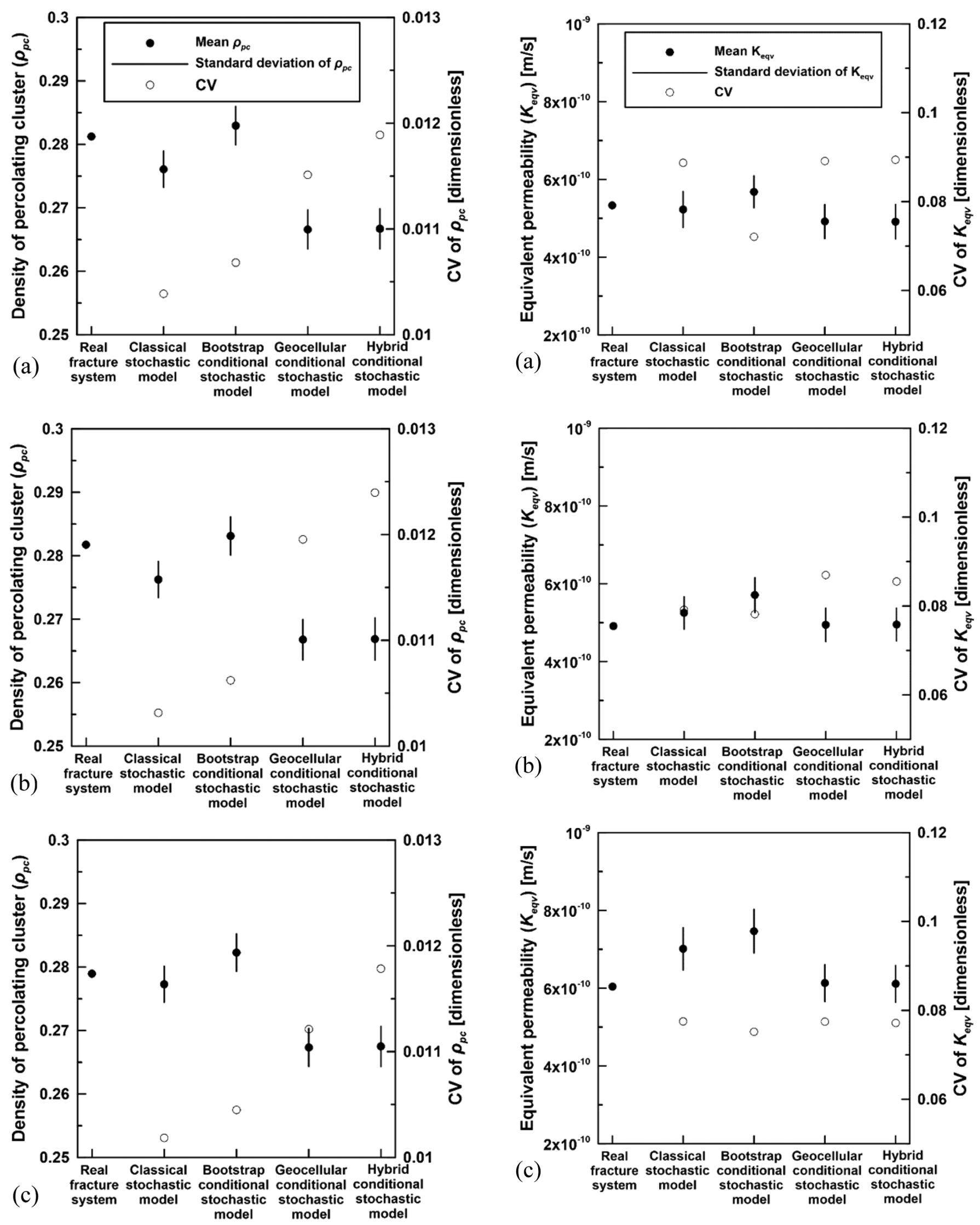

Figure 4. Density of percolating cluster ( $\rho_{p c}$ from the hypothetic real fracture system and mean $\rho_{p c}$ and $C V$ from various stochastic models in the (a) EW, (b) NS, and (c) TB directions.

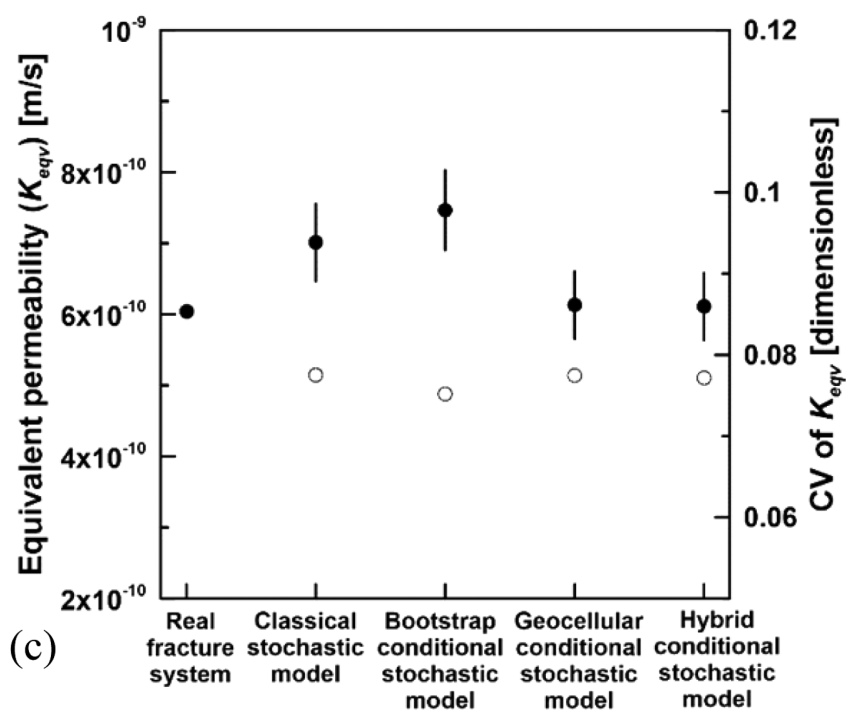

Figure 5. Equivalent permeability ( $\left.K_{\text {equ}}\right)$ from the hypothetical real fracture system and mean $K_{\text {eqv }}$ and $C V$ from various stochastic models in the (a) $\mathrm{EW}$, (b) NS, and (c) TB directions. 
were closer to the actual $K_{\text {eqv }}$ in the EW direction, while the classical, geocellular, and hybrid conditional models for the NS direction, and the geocellular and hybrid conditional models for the TB direction. These results are consistent with the findings of Ji et al. (2011): They found that the uncertainty in the $K_{\text {eqv }}$ of a fracture network could be reduced when more than $40 \%$ of a fracture population was conceptualized deterministically. Considering that about $1.5 \sim 2.6 \%$ of the fractures was conditioned in this study, and even characterizing exactly $10 \%$ of the fractures in a given site is practically difficult, the conditional stochastic DFN models could not reduce the uncertainty in estimating the equivalent properties of a fracture system using the classical stochastic DFN model.

\section{Summary and Conclusions}

The performance of the classical and conditional stochastic DFN models was evaluated by comparing the equivalent properties of the fracture networks generated with the stochastic models to those of the hypothetical real fracture system. A hypothetical real fracture system was assumed, and the classical, bootstrap conditional, geocellular conditional, and hybrid conditional stochastic approaches were applied to reproduce it. The fracture networks were generated with each approach, and the densities of the percolating cluster and equivalent permeability were calculated and compared to each other. The results show that the bootstrap conditional stochastic DFN model slightly improved the classical stochastic one in estimating the geometric connection by the fracture network. However, in estimating the hydraulic connection, the performance of the conditional stochastic models was similar to the classical stochastic model.

The equivalent properties show the overall behavior of a fracture network. When the safety of a subsurface repository for HLW is evaluated, it is important to estimate the overall characteristics of the fracture system but it is also important to estimate its local behaviors because the local characteristics determine the migration paths of nuclides. Clemo and Smith (1997) suggested that some fractures played a more important role for transport than others. Although the conditional approaches did not significantly improve the uncertainty of the classical stochastic DFN model in estimating the overall characteristics, it may help to predict the local behavior of the fracture system, which should be studied in the future.

\section{Acknowledgements}

This work was supported by the Nuclear Research and Development Program of the National Research Foundation of Korea (NRF) funded by the Ministry of Science and ICT (No. 2017M2A8A5014858).

\section{References}

Bear, J., 1993, Modeling flow and contaminant transport in fractured rocks. In: Bear, J., Tsang, C.-F., and de Marsily, G. (Eds.), Flow and Contaminant Transport in Fractured Rock. Academy Press, Inc., San Diego, pp. 1-35.
Bogdanov, I.I., Mourzenko, V.V., Thovert, J.-F., and Adler, P.M., 2007, Effective permeability of fractured porous media with power-law distribution of fracture sizes. Physical Review E, v. 76, 036309, doi:10.1103/PhysRevE.76.036309

Bym, T., Fox, A., and Josephson, N., 2014, Development and demonstration of algorithms for conditional simulation of discrete fracture networks. Proceedings of the International Discrete Fracture Network Engineering Conference 2014. Vancouver, Canada, Abstract DFNE 2014-267.

Clemo, T., and Smith, L., 1997, A hierarchical model for solute transport in fractured media. Water Resources Research, v. 33, pp.1763-1784, doi:10.1029/97WR01005

Dershowitz, W.S., Wallman, P., and Kinrod, S., 1991, Discrete Fracture Modeling for the Stripa Site Characterization and Validation Drift Inflow Predictions, Stripa Project Technical Report 91-16. SKB, Stockholm.

Dershowitz, W.S., La-Pointe, P.R., and Doe, T.W., 2004, Advances in discrete fracture network modeling, Proceedings of the U.S. EPA/NGWA Fractured Rock Conference. Portland, pp. 882-894.

Dorn, C., Linde, N., Le Borgne, T., Bour, O., and de Dreuzy, J.-R., 2013, Conditioning of stochastic 3-D fracture networks to hydrological and geophysical data. Advances in Water Resources, v. 62, pp.79-89, doi:10.1016/j.advwatres.2013.10.005

Golder, 2018, FracMan User's Manual Release 7.7. Golder Associate Inc., Redmond, WA, $573 \mathrm{p}$.

Ji, S.-H., Park, Y.-J., and Lee, K.-K., 2011, Influence of fracture connectivity and characterization level on the uncertainty of the equivalent permeability in statistically conceptualized fracture networks. Transport in Porous Media, v. 87, pp. 385-395, doi:10.1007/s11242-010-9690-9

Ji, S.-H., Park, K.W., Lim, D.-H., Kim, C., Kim, K.S., and Dershowitz, W., 2012, A hybrid modeling approach to evaluate the groundwater flow system at the low- and intermediate-level radioactive waste disposal site in Gyeong-Ju, Korea. Hydrogeology Journal, v. 20, pp. 1341-1353, doi:10.1007/s10040-012-0875-x

Ji, S.-H., and Koh, Y.-K., 2017, Appropriate domain size for groundwater flow modeling with a discrete fracture network model. Groundwater, v. 55, pp. 51-62, doi:10.1111/gwat.12435

Koohbor, B., Fahs, M., Hoteit, H., Doummar, J., Younes, A., and Belfort, B., 2020, An advanced discrete fracture model for variably saturated flow in fractured porous media, Advances in Water Resources, v. 140, 103602, doi:10.1016/j.advwatres.2020.103602

La Pointe, P.R., Hemanson, J., and Dunleavy, M., 2004, Development and validation of a fractured reservoir model for the Circle Ridge Field, Wind River Basin, WY, Annual Meeting, American Association of Petroleum Geologists. Dallas, Abstract 85792.

Miller, I., Lee, G. and Dershowitz, W., 1999, MAFIC Matrix/Fracture Interaction Code with Heat and Solute Transport User Documentation ver. 1.6. Golder Associate Inc., Seattle, WA.

Mourzenko, V.V., Thovert, J.-F., and Adler, P.M., 2004, Macroscopic permeability of three-dimensional fracture networks with power-law size distribution. Physical Review E, v. 69, 066307, doi:10.1103/PhysRevE.69.066307

Park, Y.J., Sudicky, E.A., McLaren, R.G., and Sykes, J.F., 2004, Analysis of hydraulic and tracer response tests within moderately fractured rock based on a transition probability geostatistical approach. Water Resources Research, v. 40, W12404, doi:10.1029/2004WR003188

Posiva, 2012, Safety Case for the Disposal of Spent Nuclear Fuel at Olkiluoto - Description of the Disposal System 2012, POSIVA 2012-05. Posiva Oy, Olkiluoto, $166 \mathrm{p}$.

Ramasomanana, F., Fahs, M., Baalousha, H.M., Barth, M., and Ahzi, S., 2018, An Efficient ELLAM Implementation for Modeling Solute Transport in Fractured Porous Media. Water, Air, \& Soil Pollution, v. 229, 46, doi:10.1007/s11270-018-3690-8

Schwartz, F.W., Sudicky, E.A., McLaren, R.G., Park, Y.-J., Huber, M., and Apted, M., 2010, Ambiguous hydraulic heads and ${ }^{14} \mathrm{C}$ activities in transient regional flow. Groundwater, v. 48, pp. 366-379, doi:10.111/j. 
1745-6584.2009.00655.x

SKB, 2011, Site Selection - Siting of the Final Repository for Spent Nuclear Fuel, R-11-07. SKB, Stockholm, 108 p.

Stauffer, D, and Aharony, A., 1991, Introduction to Percolation Theory, 2nd Ed. Taylor \& Francis Ltd., London, UK, 181 p.

Thury, M, Gautschi, A., Mazurek, M., Muller, W.H., Naef, H., Pearson, F.J., Vomvoris, S., and Wilson, W., 1994, Geology and Hydrogeology of the Crystalline Basement of Northern Switzerland: Synthesis of Regional Investigations 1981-1993 within the Nagra Radioactive Waste Disposal Programme, NTB93-01, Nagra, Wettingen, 316 p.

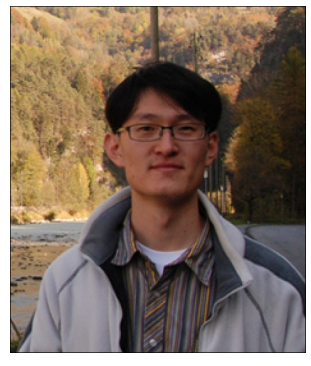

Sung-Hoon $\boldsymbol{J i}$ is a principal researcher in Radioactive Waste Disposal Research Division at Korea Atomic Energy Research Institute. His main research focuses on understanding the uncertainty in characterization and mathematical conceptualization of the hydrogeological properties of crystalline fractured rock. 